Article

\title{
Design and Characterization of New D-A Type Electrochromic Conjugated Copolymers Based on Indolo[3,2-b]Carbazole, Isoindigo and Thiophene Units
}

\author{
Yuling Zhang ${ }^{1,2}$, Shuang Chen ${ }^{1, *}$, Yan Zhang ${ }^{2}$, Hongmei Du ${ }^{2}$ and Jinsheng Zhao ${ }^{2,3, *}$ (i) \\ 1 State Key Laboratory of Heavy Oil Processing, College of Chemical Engineering, China University of \\ Petroleum (East China), QingDao 266580, China; 18866264190@163.com \\ 2 Shandong Key Laboratory of Chemical Energy Storage and Novel Cell Technology, Liaocheng University, \\ Liaocheng 252059, China; zy@lcu.edu.cn (Y.Z.); duhongmei@lcu.edu.cn (H.D.) \\ 3 College of Chemistry and Chemical Engineering, Liaocheng University, Liaocheng 252059, China \\ * Correspondence: chsh1030@163.com (S.C.); j.s.zhao@163.com (J.Z.)
}

Received: 28 August 2019; Accepted: 6 October 2019; Published: 8 October 2019

\begin{abstract}
Two new donor-acceptor (D-A) type organic conjugated random copolymers were successfully synthesized by three-component Stille coupling polymerization of indolo[3,2-b]carbazole (ICZ), isoindigo (IID) and thiophene units, namely PITID-X ( $X=1$ and 2), with the controlled monomer feed ratios of 3:1:4 and 1:1:2, respectively. The strategy of incorporating different alkyl-branched donor/acceptor units and raw material feed ratios facilitated the improvement of optical properties, solubility, conjugated structure, and electrochromic performance. Cyclic voltammetry, UV-vis-NIR absorption spectra, kinetic and colorimetric measurements of the spray-coated films were recorded in the fabricated three-electrode cells. The results showed that PITID-2, whose optical/electrical properties were better than that of PITID-1, was the candidate electrochromic material due to low band gap of $1.58 \mathrm{eV}$ accompanying the color changing from cyan (neutral state) to gray (oxidized state). The copolymer also illustrated fast bleaching/coloration response time of 2.04/0.33 and 1.35/1.50 s in a $4 \mathrm{~s}$ time interval, high coloration efficiency of 171.52 and $153.08 \mathrm{~cm}^{2} \mathrm{C}^{-1}$ and stable optical contrast of $18 \%$ and $58 \%$ at the wavelength of 675 and $1600 \mathrm{~nm}$, respectively.
\end{abstract}

Keywords: Indolo[3,2-b]carbazole; isoindigo; electrochromism; conjugated polymers; stille coupling

\section{Introduction}

$\Pi$-conjugated organic polymers that have inherently remarkable electron or hole-transporting properties have been intensively investigated in optoelectronic materials for their huge potential application in various semiconductor devices, including electrochromic devices [1-4]. Comparing with inorganic electrochromic materials, organic conductive materials have the advantages of facile processing, convenient color control, and tunability in structure modification. The researchers have designed and synthesized many molecular units with donor-acceptor (D-A) structures using chemical or electrochemical polymerization. Following the D-A strategy, energy band-gap levels, structural characteristics, and electrochromic properties can be easily adjusted by introducing different monomer units and side chains [5,6]. The well-matched donor and acceptor units are widely used in low-band-gap copolymers, which contributes to the significant improvement of intramolecular charge transfer ability and the enhancement of conjugated backbone length with higher onset absorption wavelength and absorption intensity [7-9]. 
Among the versatile donors, acceptors, and their derivatives, the novel building blocks of indolo[3,2-b]carbazole (ICZ) and isoindigo (IIG) units have raised the researchers' much attention [10,11]. ICZ is a well-performance electroactive organic chromophore commonly used as a donor due to its more rigid and extended conjugated structure than carbazole and indolo[3,2-b]indole units. [12,13]. Indolo[3,2-b]carbazole derivatives, whose 5,11-position can be substituted by long alkyl, aryl side chains, or other pendant units, contribute to modification of the $\pi-\pi$ stacking and lamella structure on the stacked conjugated polymers [14-16]. The 2,8- substitution positions of ICZ monomer can be brominated or electrochemically polymerized. The corresponding derivatives have been explored intensively for their excellent photoelectronic performance in organic semiconductor devices [17]. Two redox-active diphenylamine blocks were introduced to the ICZ-based polymers. The obtained materials showed reversible near-infrared electrochromic and electroluminochromic properties with a high emission quantum yield of 30\% [16]; Mula S et al. compared three kinds of ICZ-based complexes and the materials illustrated adjustable features and promising application in functional materials by density functional calculation [18]; Ethylbenzene, octyloxylbenzene, ethyloxylbenzene, and $\mathrm{N}, \mathrm{N}$-diethylaniline units were introduced to ICZ-based conjugate structure, the results illustrated wide absorption range and good light-harvesting ability in solar cells [19]. Our group and other researchers synthesized versatile ICZ derivatives to obtain functional conjugate structures and investigated their charge transporting, hole-transporting abilities and electrochromic properties in devices [20-22]. In addition, indolo[3,2-b]carbazole derivatives have been widely used as excellent organic lighting-emitting diodes (OLED) or organic field-effect transistors (OFEDs) due to their excellent hole-transporting properties. The novel rigid unit has drawn much attention as excellent photo- and electro- active or aggregation-induced fluorescence materials for adjustable the highest occupied molecular orbital/the lowest unoccupied molecular orbital (HOMO/LUMO) levels and energy band gap.

An isoindigo-based (IID) unit, a derivative of indigo, is an important organic conjugated candidate in conventional dye industry, as the material can be obtained from sustainable natural resources [23]. The nitrogen and oxygen atoms in the two lactam rings contribute to form intramolecular hydrogen bond and planar structure. This can enhance the effective conjugation length and $\pi-\pi$ interaction leading to a narrow energy band gap and high extinction coefficiency [24,25]. The branched alkyl side chains of isoindigo-based derivatives have also been studied for electroluminescent devices and organic photovoltaic materials due to the advantages of its wide absorption range in the visible $(380-730 \mathrm{~nm})$ and near infrared region with large onset absorption wavelengths [26]. The strategy of introducing different side chains was applied to adjust the polymer solubility via the method of replacing the hydrogen atoms of the core unit. The properties of narrow band gap, broad absorption profiles can also be slightly adjusted. Romain et al. characterized a series of isoindigo-based copolymers to explore the properties of p-type and n-type charge transport in the thin films with thiophene-based blocks, the results illustrated potential application in electrochromic areas $[27,28]$. It is interesting to investigate the electrochromic properties of the copolymers consisting of indolo[3,2-b]carbazole, isoindigo and thiophene units.

We were motivated by the successive application of the D-A type organic conjugated polymer in organic optoelectronic areas, including electrochromism. The alternating donor and acceptor units could contribute to partial isolation of the frontier molecular orbitals. The donor unit contributes a lot to the HOMO levels, while the LUMO levels have more acceptor character [29]. Herein, we reported the synthesis and characterization of the two D-A type three-component copolymers based on ICZ, IID and thiophene units, namely PITID-1 and PIDIT-2, with long alkyl substituted side chains. The copolymers were synthesized via Stille cross-coupling polymerization method with high yields. ${ }^{1} \mathrm{H}$ NMR, XPS and IR tests were conducted to confirm the structures of the two new random copolymers. The two solution-processable copolymers were spray-coated onto the conductive slide of indium tin oxide glasses (ITO), serving as working electrode. Additionally, the Ag wire and $\mathrm{Pt}$ wire were used as the pseudo-reference electrode and counter electrode, respectively. The cyclic 
voltammetry, absorption profiles, kinetic curves, and stability measurements were carried out to compare the corresponding electrochromic properties of the two copolymer films via UV-vis-NIR spectrophotometer, which was used in conjunction with electrochemical workstation.

\section{Instrumentation and Materials}

\subsection{Instrumentation}

${ }^{1} \mathrm{H}$ NMR spectra of the two copolymers were recorded with deuterated chloroform $\left(\mathrm{CDCl}_{3}\right.$, Cambridge Isotope Laboratories, Inc., Andover, USA) as solvent and tetramethylsilane (TMS) as internal standard with the equipment of Advance NEO $500 \mathrm{MHz}$ spectrometer (Bruker BioSpin International AG, Switzerland). Cyclic voltammetry was carried out at the scan rate of $0.1 \mathrm{~V} / \mathrm{s}$ from $-2 \mathrm{~V}$ to $1.8 \mathrm{~V}$ with the CHI660D electrochemical workstation (Chen Hua Instrument Co., Ltd, Shanghai, China) in the self-fabricated three-electrode cell. The classical system used polymer-sprayed indium tin oxide (ITO, Zhuhai Kaivo Optoelectronic Technology Co., Ltd, Guangdong, China) substrate, Ag wire, and $\mathrm{Pt}$ wire serving as working electrode, pseudo-reference electrode, and counter electrode, respectively. A $0.2 \mathrm{M} \mathrm{TBAPF}_{6} / \mathrm{ACN}$ electrolyte solution was used during the electrochemical measurements, including cyclic voltammetry, kinetics, colorimetry and memory measurements. The redox peaks of ferrocenium/ferrocene $\left(\mathrm{Fc}^{+} / \mathrm{Fc}\right)$ solution were carried out to calibrate $\mathrm{Ag}$ wire to normalize HOMO/LUMO energy levels [30]. The UV-vis-NIR spectroelectrochemistry and kinetic spectra were recorded via Varian Cary 5000 spectrophotometer (Agilent Technologies Ltd, Mulgrave, Australia) which is used in conjunction with CHI660D electrochemical workstation by switching the stepwise voltages from neutral state to oxidized state. X-ray photoelectron spectroscopy (XPS) analyses of the copolymer films were measured on a thermo Escalab $\mathrm{Xi}^{+}$(ThermoFisher Scientific, Waltham, USA) with a monochromated Al X-ray resource. Fourier transform infrared spectroscopy (FT-IR) was recorded in a Nicolet 6700 FTIR spectrometer (Thermo Nicolet Co., Wisconsin, USA), using potassium bromide as a carrier. Thermogravimetric analysis (TGA, TG, NETZSCH Scientific Instruments Trading Ltd., Germany) was measured to record the thermal stability of the two random copolymers at the heating rate of $10^{\circ} \mathrm{C} / \mathrm{min}$ from 20 to $750{ }^{\circ} \mathrm{C}$. The pictures of spray-coated films at different redox states and as polymer solution were pictured by a canon camera. The information on molecular weight was obtained by gel permeation chromatography (GPC) analysis (Waters Co., Milford Massachusetts, USA), which was carried out on a waters 2414 system with a UV-detector. The test temperature was $80^{\circ} \mathrm{C}$, and the mobile phase was 1,2,4-trichlorobenzene, and polystyrene was used as the standard, a PSS SDV analytical column $(5 \mu \mathrm{m}, 300 \mathrm{~mm} \times 8.0 \mathrm{~mm}, 10000 \AA)$ was used for the measurement. Elemental analyses were performed with a PerkinElmer EA 2400 II elemental analyzer (Elementar Trading Co., Ltd, USA).

\subsection{Materials}

All the reaction reagents and solvents were all purchased directly from commercial sources and used without further purification unless specifically noted. The monomer M1 and M2 were synthesized according to the reported synthetic procedures in the literatures with slightly modification [17,22]. The synthetic details and characterization data of the monomers M1, M2 have been reported previously in our group [22]. 2,5-bis(trimethylstannyl)thiophene and (E)-6,6'-dibromo-1,1'-bis(2-octyldodecyl)-[3,3'-biindolinylidene]-2,2'-dione were directly purchased from commercial resources (Derthon Optoelectronic Materials Science Technology Co., Ltd, Shenzhen, China) and used without further purification. Two isoindigo-based random copolymers PITID-X $(X=1$ and 2) were synthesized by Stille cross-coupling polymerization with indolo[3,2-b]carbazole derivative and thiophene blocks in different raw material feed ratios of 1:3:4 and 1:1:2, respectively. The synthetic routes were shown in Scheme 1. 

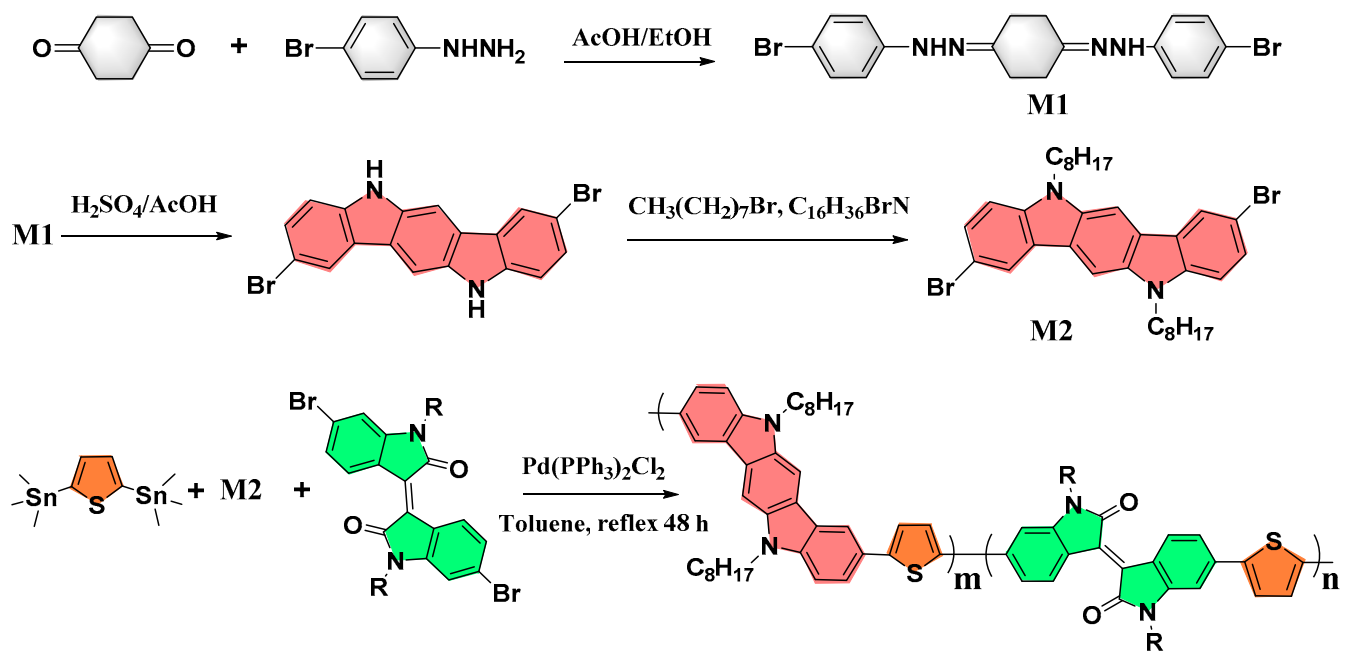

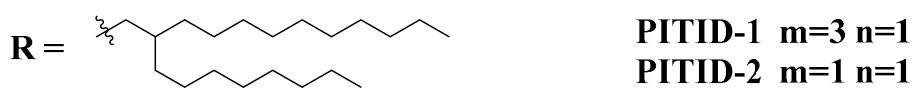

Scheme 1. The synthetic route of the conjugated polymers PITID-1 and PITID-2.

\subsection{Synthesis of Monomers}

The synthesis routes of the monomers M1 and M2 and the corresponding copolymers were presented in the Scheme 1. The intermediate monomers 2,8-dibromo-5,11-dihydrol-indolo[3,2-b] carbazole and 2,8-dibromo-5,11-dioctyl-indolo[3,2-b]carbazole were synthesized via the method of double fisher idolization according to the previous literature procedures $[17,22]$.

\subsection{Synthesis of Copolymer PITID-1}

The monomers 2,5-bis(trimethylstannyl)thiophene (200 $\mathrm{mg}, \quad 0.4881 \mathrm{mmol})$, (E)-6,6'-dibromo-1,1'-bis(2-octyldodecyl)-[3,3'-biindolinylidene]-2,2'-dione (119.72 mg, $0.1220 \mathrm{mmol}$ ), 2,8-dibromo-5,11-dioctyl-5,11-dihydroindolo[3,2-b]carbazole $(233.8 \mathrm{mg}, 0.3661 \mathrm{mmol})$, and the catalyst bis(triphenyl-phosphine)Palladium(II)Dichloride ( $\left.\mathrm{Pd}\left(\mathrm{PPh}_{3}\right)_{2} \mathrm{Cl}_{2}\right)(20 \mathrm{mg}, 0.0282 \mathrm{mmol}, 5.78 \mathrm{~mol} \%)$ were added into a round flask with $40 \mathrm{~mL}$ anhydrous toluene solution. The reaction apparatus were purged and re-filled with argon at least three times to remove excess air. The reaction mixture solution was stirred at $110^{\circ} \mathrm{C}$ for $48 \mathrm{~h}$, then cooled down to room temperature. The toluene solvent was removed under reduced pressure. The residues obtained after vacuum distillation of toluene solvent were re-dissolved in a small amount of chloroform, and then be precipitated by cold methanol. The crude product was obtained by filtration, and then subjected to the following purification steps by the soxhlet extraction method. In the soxhelt extraction procedure, the eluents selected in turn were $\mathrm{n}$-hexane, anhydrous methanol, and acetone, successively. After drying under vacuum, the polymer as dark black solid was collected with a yield of $74 \% .{ }^{1} \mathrm{H}$ NMR $(500 \mathrm{MHz}$, Chloroform- $d$ ) was given in Figure S1a (in Supplementary Materials), and the shifts of the hydrogen atoms and the assignments of their corresponding peaks are also given in the Figure S1a (in Supplementary Materials). A, Table 1 listed the molecular weight of the two polymers, including the number-average molecular $\left(M_{\mathrm{n}}\right)$, the weight-average molecular $\left(M_{\mathrm{w}}\right)$, and the polymer dispersity index (PDI) etc. The data for $M_{\mathrm{n}}, M_{\mathrm{w}}$, PDI of PITID-1 were 20.1, 27.5 kDa, and 1.37, respectively. Elemental analysis result: Anal. Calcd for PITID-1: C, 80.75; H, 8.72; S, 4.96; N, 4.33; Found: C, 80.48; H, 8.35; S, 5.02; N, 4.45.

\subsection{Synthesis of Copolymer PITID-2}

Compared with the synthesis produce of PITID-1, the reaction precursors 2,5bis(trimethylstannyl)thiophene (300 mg, $0.7322 \mathrm{mmol}$ ), (E)-6,6'-dibromo-1,1'-bis(2-octyldodecyl)-[3,3'biindolinylidene]-2,2'-dione ( $344.4 \mathrm{mg}, 0.3661 \mathrm{mmol}$ ), and 2,8-dibromo-5,11-dioctyl-5,11-dihydroindolo [3,2-b]carbazole $(234 \mathrm{mg}, 0.3665 \mathrm{mmol})$, and the catalyst bis(triphenyl-phosphine)Palladium 
(II)Dichloride ( $\mathrm{Pd}\left(\mathrm{PPh}_{3}\right)_{2} \mathrm{Cl}_{2}, 30 \mathrm{mg}, 0.04274 \mathrm{mmol}, 5.84 \mathrm{~mol} \%$ ) were added into a round flask with $40 \mathrm{~mL}$ toluene solution. The synthesis and processing produres were the same as PITID-1. The dark black solid was collected with a yield of $73 \%$. The ${ }^{1} \mathrm{H}$ NMR spectrum of PITID-2 was shown in Figure S1b, and the shifts of the hydrogen atoms and the assignments of their corresponding peaks are also given in Figure S1b. Table 1 illustrated the data for $M_{n}, M_{\mathrm{w}}$, and PDI, which were 17.7, 23.7 kDa, and 1.34, respectively. Elemental analysis result: Anal. Calcd for PITID-2: C, 80.27; H, 9.35; S, 4.37; N, 3.82. Found: $\mathrm{C}, 80.01 ; \mathrm{H}, 8.91 ; \mathrm{S}, 4.45$, and $\mathrm{N}, 4.01$.

\section{Results and Discussions}

\subsection{FT-IR Spectra of the Two Polymers}

To confirm the structures of the random copolymers with different donor/acceptor monomers, including thiophene, isoindigo, and indolo[3,2-b]carbazole derivative units, the FT-IR spectra of the two materials PITID-X ( $X=1$ and 2$)$ were measured and illustrated in Figure 1 . The transmittance curves showed that several similar characteristic peaks were identified due to the asymmetrical stretching vibration or the skeletal vibration of specific chemical bond/groups. For the polymer PITID-1, the peaks, including $2922 \mathrm{~cm}^{-1}$ (asymmetrical stretching vibration of $-\mathrm{CH}_{2}-$ group), $2851 \mathrm{~cm}^{-1}$ (symmetrical stretching vibration of $-\mathrm{CH}_{2}$ - group) were observed for the alkyl side chains in IIG or ICZ. The peak at $1690 \mathrm{~cm}^{-1}$ corresponded to the stretching vibration of ketone $(\mathrm{C}=\mathrm{O})$ in the isoindigo unit. Three peaks at $1607,1508,1452 \mathrm{~cm}^{-1}$ may derive from the skeletal vibration of the thiophene, ICZ, or IIG ring. The peak at $1313 \mathrm{~cm}^{-1}$ referred to the $-\mathrm{C}-\mathrm{N}$ - stretching vibration of IIG or ICZ groups. The absorption peaks at $1170 \mathrm{~cm}^{-1}, 1111 \mathrm{~cm}^{-1}$ were assigned to the in plane bending vibration of the $\mathrm{C}-\mathrm{H}$ bonds alongside the skeleton of the whole polymer chain. Other peaks at 872,787 , and $718 \mathrm{~cm}^{-1}$ were due to the out-of-plane bending vibration of $\mathrm{C}-\mathrm{H}$ in the aromatic rings. For FT-IR spectra of the PITID-2, the positions of characteristic peaks were similar to that of PITID-1, although the absorption intensity owed a slight difference. The results showed that the backbones of the two copolymers both contained the monomeric units mentioned above [31].

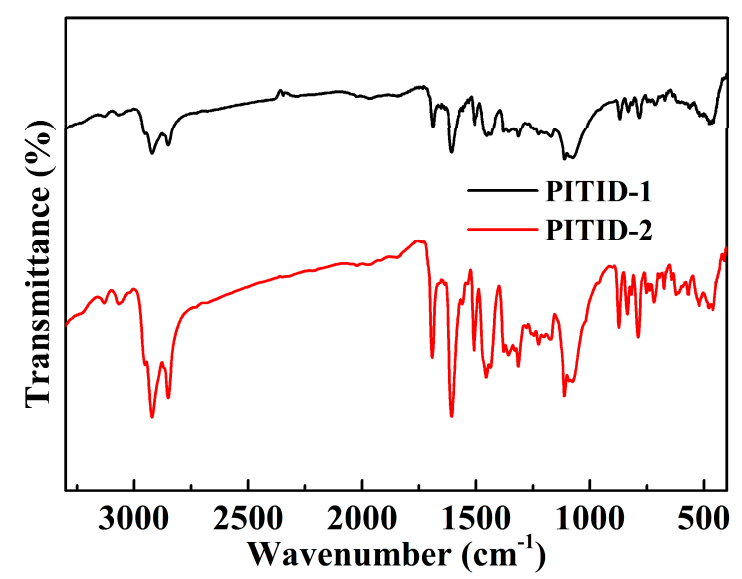

Figure 1. FTIR spectra of the two compounds PITID-1 (black line) and PITID-2 (red line).

\subsection{XPS Profiles of Polymer Films}

In order to investigate the elemental compositions of carbon, nitrogen, oxygen, and sulphur atoms along the copolymer backbones, the materials PITID-1 and PITID-2 were characterized by X-ray photoelectron spectra (XPS) measurements. The results were recorded and shown in Figure 2 and Figure S2 (supporting information). Comparing the XPS profiles of the two copolymers, the two materials illustrated similar chemical state and bond energy intensity.

Taking the polymer PITID-2 for example, the survey scan revealed the presence of the four elements including carbon, nitrogen, sulphur, and oxygen, as shown in Figure 2a. The $C$ 1s gross peak 
of the random copolymer PITID-2 can be deconvoluted into three peaks, as illustrated in Figure $2 \mathrm{~b}$. The peak located at a binding energy (B.E.) of $284.0 \mathrm{eV}$ originated from $\underline{\mathrm{C}}-\mathrm{H}$ throughout the whole backbone. The peak located at $284.5 \mathrm{eV}$ was attributed to $\underline{C}=\mathrm{C}$, which can be originated from the carbon atoms in the aromatic skeleton $(\mathrm{C}=\mathrm{C})$ of the monomers including ICZ, IIG, and thiophene blocks. The component located at $285.0 \mathrm{eV}$ was assigned to $\underline{C}-\mathrm{S}, \underline{\mathrm{C}}-\mathrm{N}$ bonds of the three monomeric units. The N 1s peak shape (shown in Figure 2c) can be deconvoluted into two peaks, the peak at $399.5 \mathrm{eV}$ can be attributed to $\mathrm{C}-\mathrm{N}-\mathrm{C}$ of the isoindigo block [32]. And the component at $400.0 \mathrm{eV}$ is a typical position of a $\mathrm{C}-\mathrm{N}-\mathrm{C}$ bond in an ICZ unit. [33]. The relative filled areas of the two peaks in $\mathrm{N} 1$ s correspond to the feed ratios of IIG and ICZ units, respectively. The $S 2 \mathrm{p}$ spectra illustrated in Figure $2 \mathrm{~d}$ can be assigned to typical deconcvoluted S 2p3/2 $(163.7 \mathrm{eV})$ and S 2p1/2 $(164.8 \mathrm{eV})$ spin orbit splitting peaks, which was originated from $\mathrm{C}-\underline{\mathrm{S}}$ of the thiophene block. Figure 2e illustrated that two peaks of the $\mathrm{O} 1 \mathrm{~s}$ profile can be deconvoluted, the peak located at $531.8 \mathrm{eV}$ can be attributed to $\mathrm{C}=\underline{\mathrm{O}}$ unit of isoindigo block and the peak at $530.8 \mathrm{eV}$ can be attributed to the metal oxide in ITO substrates. Similar results were obtained from the polymer PITID-1 (Figure S2 in Supplementary Materials). XPS curves of the two polymers showed that the random copolymers were successfully synthesized by incorporating the three monomers, indolo[3,2-b]carbzazole, isoindigo and thiophene units with different feed ratios.
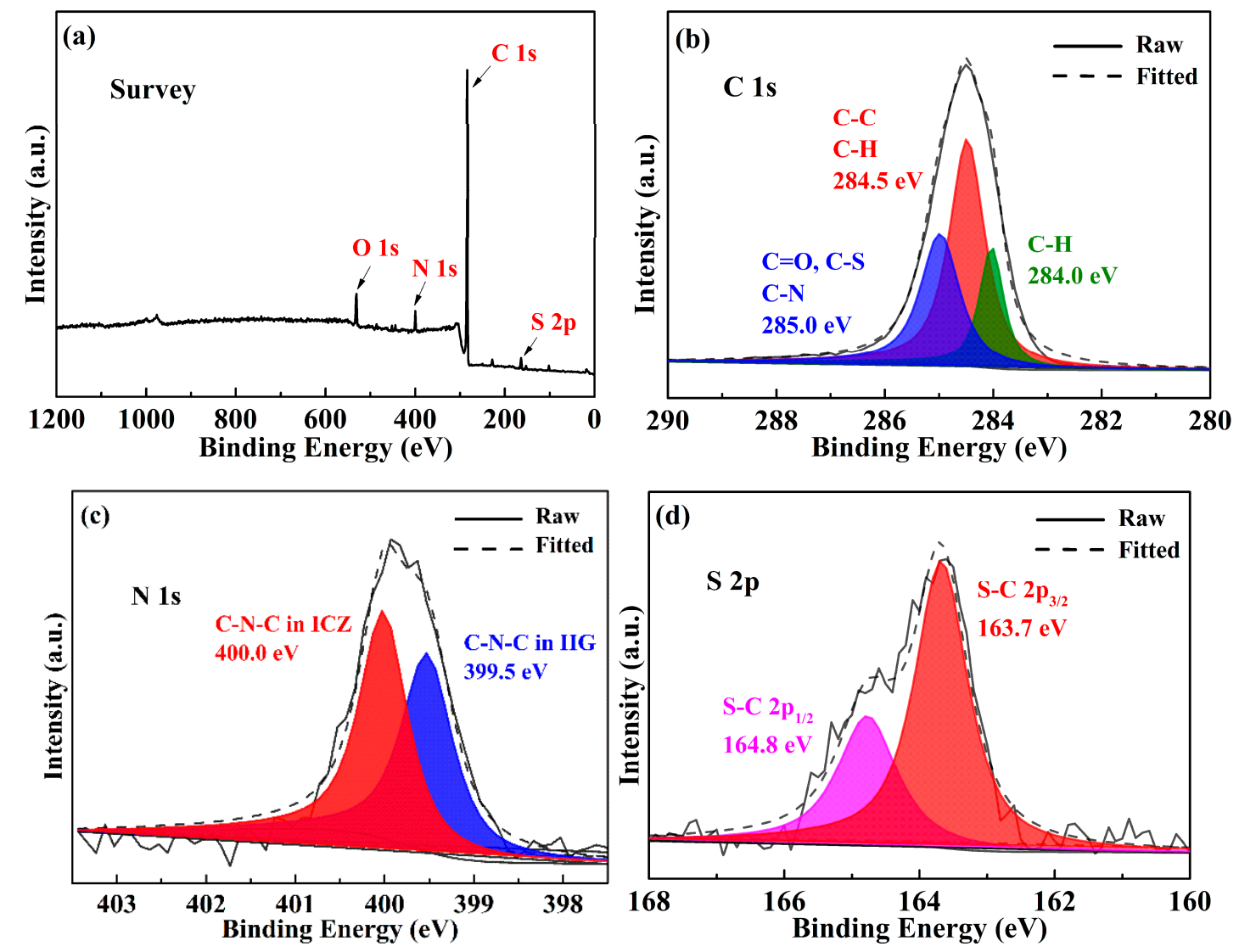

Figure 2. Cont. 


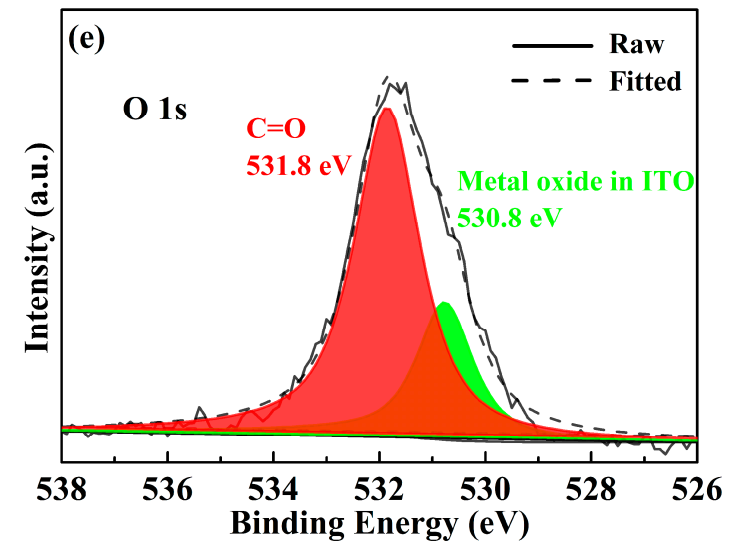

Figure 2. High-resolution X-ray photoelectron spectroscopy (XPS) spectra of the chemical-polymerized copolymer PITID-2 thin films: (a) Survey, (b) C 1s, (c) N 1s, (d) S 2p, (e) O 1s. The raw curve and the fitted curve were shown in solid and dotted lines, respectively.

\subsection{Electrochemical Properties}

In order to investigate the electrochemical properties of the materials, both of the random copolymers, dissolved fully in chloroform, were spray-coated homogeneously onto the conductive slide of the ITO substrates. The cyclic voltammetry tests of the copolymer films were conducted in the self-fabricated three-electrode system. The ITO glass substrates, Ag wire, and Pt wire were used as the working electrode, pseudo-reference electrode, and counter electrode, respectively. Cyclic voltammetry tests were carried out at the scan rate of $100 \mathrm{mV} / \mathrm{s}$ in a $0.2 \mathrm{M} \mathrm{TBAPF}_{6} / \mathrm{ACN}$ electrolyte solution between 0 and $1.8 \mathrm{~V}$, accompanying the obvious redox peaks and instant color variation of the films. The variation can be originated from the emergence and disappearance of charge carriers, including polaron and bipolarons.

As shown in Figure 3, the copolymers illustrated one obvious reversible redox peak at 1.43/0.86 V and 1.20/0.97 V for PITID-1 and PITID-2, respectively, during the p-type doping process. However, no obvious redox peaks were observed during the n-type doping scanning for the two polymers, it may originate from unstable anion radicals that can be easily disturbed by oxygen or water in the ambient conditions accompanying the transportation of the anions in the supporting electrolyte. For the polymer PITID-1 and PITID-2 (shown in Figure 3), the onset oxidation potentials ( $\left.E_{\text {onset,ox }}\right)$ were $0.79 \mathrm{~V}$ and $0.68 \mathrm{~V}$, respectively. Compared with PITID-1, the lower values of $E_{\text {onset,ox }}$ for PITID-2 may result from the smooth charge transfer between the donor and acceptor units due to the increased acceptor content (isoindigo unit).
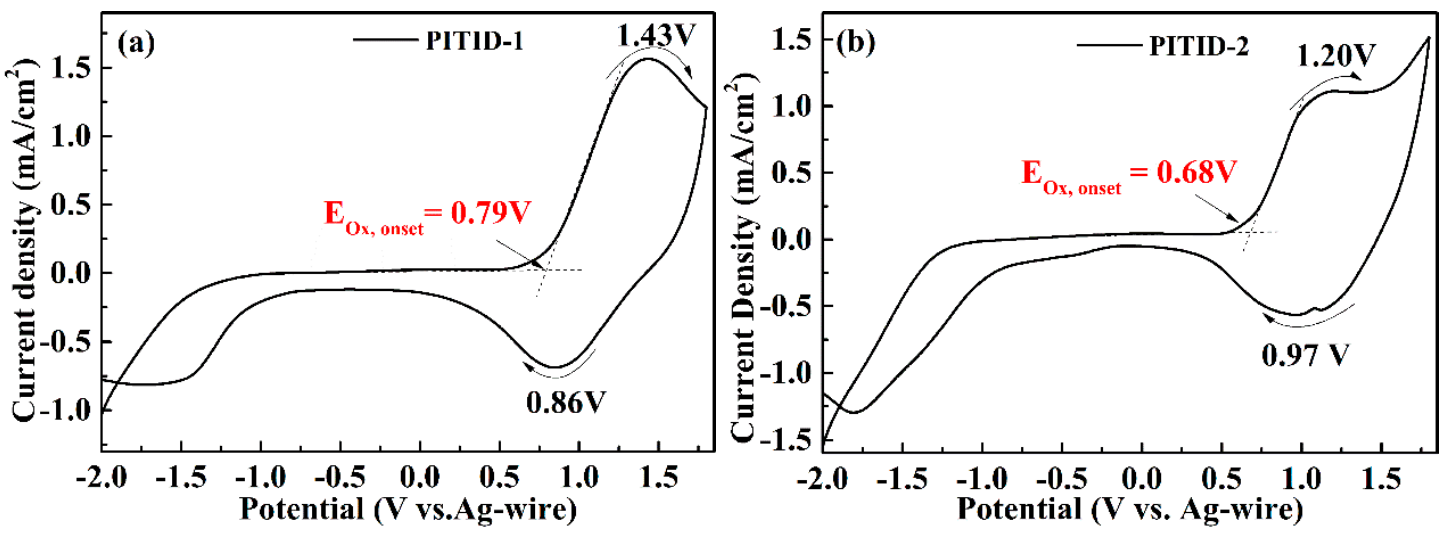

Figure 3. C-V curves of the copolymer films, PITID-1 (a) and PITID-2 (b), on the spray-coated indium tin oxide (ITO) substrates in $0.2 \mathrm{M} \mathrm{TBAPF}_{6} / \mathrm{ACN}$ electrolyte solution at a scan rate of $100 \mathrm{mV} / \mathrm{s}$ between -2 and $1.8 \mathrm{~V}$. 
Table 1. Electrochemical data and molecular weights of the PITID-1 and PITID-2.

\begin{tabular}{cccccccc}
\hline \multirow{2}{*}{ Copolymer } & $\mathbf{M n}$ & $\mathbf{M w}$ & \multirow{2}{*}{ PDI } & Yield & $\boldsymbol{E}_{\text {onset,ox }}$ & Redox Peak \\
\cline { 2 - 3 } \cline { 6 - 7 } & $\mathbf{k D a}$ & $\mathbf{k D a}$ & & & $\mathbf{N}$ & $/ \mathbf{V}$ \\
\hline PITID-1 & 20.1 & 27.5 & 1.37 & 74 & 0.79 & $1.43 / 0.86$ \\
PITID-2 & 17.7 & 23.7 & 1.34 & 73 & 0.68 & $1.20 / 0.97$ \\
\hline
\end{tabular}

Estimated from CV data vs. Ag wire, in which Eonset,ox refers to the oxidation onset potentials of the polymers (vs. Ag wire electrode).

\subsection{Optical Behaviors of the Polymer Solutions and Films}

The optical properties of the two different indolo[3,2-b]carbazole-based copolymers, PITID-1 and PITID-2, in the chloroform solutions and as thin films were studied using UV-vis-NIR absorption spectroscopy. The optical behaviors were shown in Figure 4 and the corresponding optical data was summarized in Table 2. As shown in Figure 4, both of the D-A type random copolymers possessed dual-absorption peaks with strong absorption intensity in visible region (380-720 nm) no matter in the form of solid or solution state, which is an unique characteristic of D-A type organic conjugated polymers. Figure $4 \mathrm{a}$ illustrated that the shorter-wavelength absorption band $\left(\lambda_{\max , 1}, 300-480 \mathrm{~nm}\right)$, owing the same peak at $354 \mathrm{~nm}$, originated from the localized $\pi-\pi^{*}$ transition of indolo[3,2-b]carbazole (ICZ) and thiophene units [34]. While the longer-wavelength absorption band $\left(\lambda_{\max , 2}, 480-800 \mathrm{~nm}\right)$, centered at $658 \mathrm{~nm}$, derived from intramolecular charge transfer (ICT) from ICZ and thiophene donor units to isoindigo acceptor unit. The valley of the curve at $500 \mathrm{~nm}$ can be observed. As the content of ICZ and thiophene decreased, the shorter-wavelength absorption band centered at $354 \mathrm{~nm}$ stayed unchanged, while the longer-wavelength absorption band centered at $658 \mathrm{~nm}$ red-shifted about $6 \mathrm{~nm}$.

Compared with the spectra of polymer solutions in the visible region, the maximum absorption peaks of corresponding polymer films illustrated obvious red shift. The shorter-wavelength absorption peaks of both polymer films showed similar positions as in solution (at 355 and $353 \mathrm{~nm}$ for PITID-1 and PITID-2, respectively), whereas the longer-wavelength absorption peak shifted $6 \mathrm{~nm}$ up to 674 and $672 \mathrm{~nm}$ for PITID-1 and PITID-2, accompanying the decrease of relative intensity of two absorption bands. This behavior may be due to the aggregation effect of the polymer in the solid state. The onset absorption wavelength $\left(\lambda_{\text {onset }}\right)$ that had a negative correlation with the optical energy band gap $\left(E_{\mathrm{g}}{ }^{\mathrm{opt}}\right)$ was obtained as $795,786 \mathrm{~nm}$ and the $E_{\mathrm{g}}{ }^{\text {opt }}$ values were calculated to be 1.56 and $1.58 \mathrm{eV}$ for PITID-1 and PITID-2, respectively. From the inserted picture in Figure 4a,b, the solutions showed the colors of light cyan, dark cyan for PITID-1 and PITID-2, respectively. In the solid state, the color of the two polymers both illustrated dark gray that was not easy to identify by naked eyes.
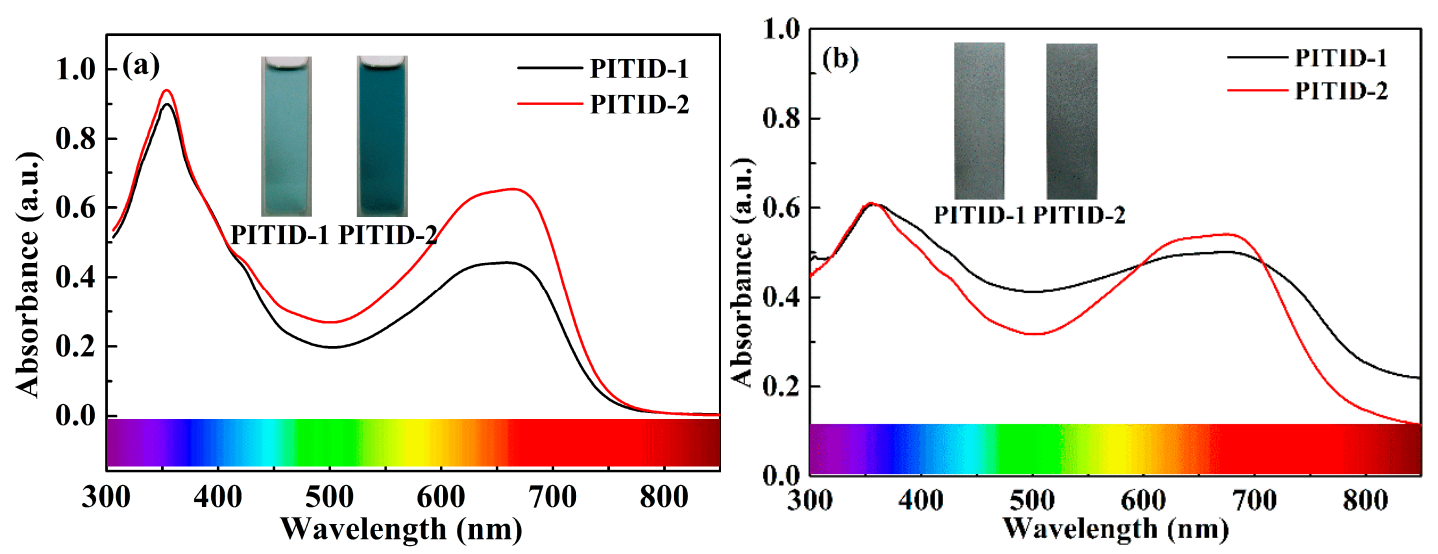

Figure 4. UV-vis absorption spectra of PITID-1 and PITID-2 in chloroform (a) and as thin films (b). The inserted pictures show the color of the polymers in different states. 
Table 2. Summary of optical and electrochemical properties of copolymers PITID-X $(X=1,2)$ in solution and as film state.

\begin{tabular}{|c|c|c|c|c|c|c|c|c|}
\hline \multirow{2}{*}{ Compound } & \multicolumn{2}{|c|}{ In Solution } & \multicolumn{2}{|c|}{ In Film State } & \multirow{2}{*}{$\frac{{ }^{\mathrm{a}} E_{\mathrm{g}}{ }^{\mathrm{opt}}}{(\mathrm{eV})}$} & \multirow{2}{*}{$\frac{{ }^{\mathrm{b}} E_{\text {onset }}}{\text { (V) }}$} & \multirow{2}{*}{$\begin{array}{c}{ }^{\mathrm{c}} \text { HOMO } \\
(\mathrm{eV})\end{array}$} & \multirow{2}{*}{$\begin{array}{c}\mathrm{d}^{\mathrm{d}} \text { LUMO } \\
(\mathrm{eV})\end{array}$} \\
\hline & $\begin{array}{l}\lambda_{\max } \\
(\mathrm{nm})\end{array}$ & $\begin{array}{c}\lambda_{\text {onset }} \\
(\mathbf{n m})\end{array}$ & $\lambda_{\max }(\mathrm{nm})$ & $\begin{array}{c}\lambda_{\text {onset }} \\
(\mathbf{n m})\end{array}$ & & & & \\
\hline PTDDB-1 & $354 ; 658$ & 744 & $355 ; 674$ & 795 & 1.56 & 0.79 & -5.04 & -3.48 \\
\hline PTDDB-2 & $354 ; 664$ & 748 & $353 ; 672$ & 786 & 1.58 & 0.68 & -4.93 & -3.35 \\
\hline
\end{tabular}

${ }^{\mathrm{a}} E_{\mathrm{g}}{ }^{\text {opt }}$ is calculated following the equation: $E_{\mathrm{g}}{ }^{\text {opt }}=1240 / \lambda_{\text {onset }}{ }^{\text {film}} ;{ }^{\mathrm{b}} E_{\text {onset }}$ data is obtained from CV curve. The oxidation peak potential for $\mathrm{Fc}^{+} / \mathrm{Fc}$ is calculated to be $0.55 \mathrm{~V}$ vs. Ag wire. ${ }^{c} E_{\mathrm{HOMO}}=-\left[4.8+\left(E_{\mathrm{onset}, \mathrm{ox}}-0.55\right)\right]$ $\mathrm{eV}^{\mathrm{d}} E_{\mathrm{LUMO}}=E_{\mathrm{HOMO}}+E_{\mathrm{g}}{ }^{\mathrm{opt}}$.

\subsection{Spectroelectrochemistry}

Spectroelectrochemical properties of the spray-casted copolymer films PITID-X $(X=1,2)$ that were deposited onto a conductive slide of ITO substrates were carried out to monitor the variation of absorption spectra ranging from 300 to $1600 \mathrm{~nm}$ as a function of different applied voltages.

The photoelectric profiles of the two polymer films at different applied voltages ranging from $0 \mathrm{~V}$ (neutral state) to $1.35 \mathrm{~V}$ (oxidized states) were recorded in Figure 5. As shown in Figure 5a, the absorption curve of PITID-1 shows two absorption peaks, in the visible region at 355 and $674 \mathrm{~nm}$ in the neutral state. The first peak $\left(\lambda_{\max , 1}\right)$ centered at $355 \mathrm{~nm}$ with a wide absorption band from 300 to $500 \mathrm{~nm}$ and the second absorption peak $\left(\lambda_{\max , 2}\right)$, centered at $674 \mathrm{~nm}$, showed a wider absorption band ranging from 500 to $960 \mathrm{~nm}$, which can be originated from $\pi-\pi^{*}$ transitions and the ICT effect. The absorption valley at $500 \mathrm{~nm}$ allowed the transmittance of cyan light, which makes the PITID-1 film show the hue of cyan. However, it is almost transparent in the NIR region. The position of two absorption peaks may be related to the monomeric units and degree of polymerization in the copolymer chains, which was related to the intermolecular charge transition along the conjugated backbones. When the applied potential increased gradually from $0 \mathrm{~V}$ to $1.35 \mathrm{~V}$, the absorption intensity of the two absorption peaks in the visible region reduced gradually and the absorption intensity in near infrared region, especially at the wavelength of $1500 \mathrm{~nm}$, simultaneously greatly increased. It can be due to the decrease of $\pi-\pi^{*}$ transition electrons and the increase of polaron and bipolaron. The generation of polaron and bipolaron may facilitate the rearrangement of polymer structures, adjustment of HOMO and LUMO energy levels, and the value of energy gap. The color of the films changed from cyan $\left(L^{*}=71.60, a^{*}=-6.79\right.$, $\left.b^{*}=0.24\right)$ to gray $\left(L^{*}=72.08, a^{*}=-0.45, b^{*}=-0.72\right)$ when the applied potentials gradually transferred from 0 to $1.35 \mathrm{~V}$. Compared with the copolymer PITID-1, the spectra of PITID-2 was recorded at same applied potential, increasing from neutral state $(0 \mathrm{~V})$ to oxidized state $(1.35 \mathrm{~V})$. As shown in Figure $5 \mathrm{~b}$, the PITID-2 film also illustrated two similar intensity absorption bands. The position of absorption peaks at $353 \mathrm{~nm}$ and $672 \mathrm{~nm}$ can be obtained. As shown in Figure 5b, the film of PITID-2 illustrated obvious color transformation between the neutral and oxidized state, accompanying the color changing from cyan to gray. The color of the film PITID-2 changed from cyan $\left(L^{*}=63.25, a^{*}=8.60, b^{*}=-1.67\right)$ to gray $\left(L^{*}=65.15, a^{*}=0.45, b^{*}=2.15\right)$ when the applied potentials transferred from the neutral state to the full-oxidized state. 

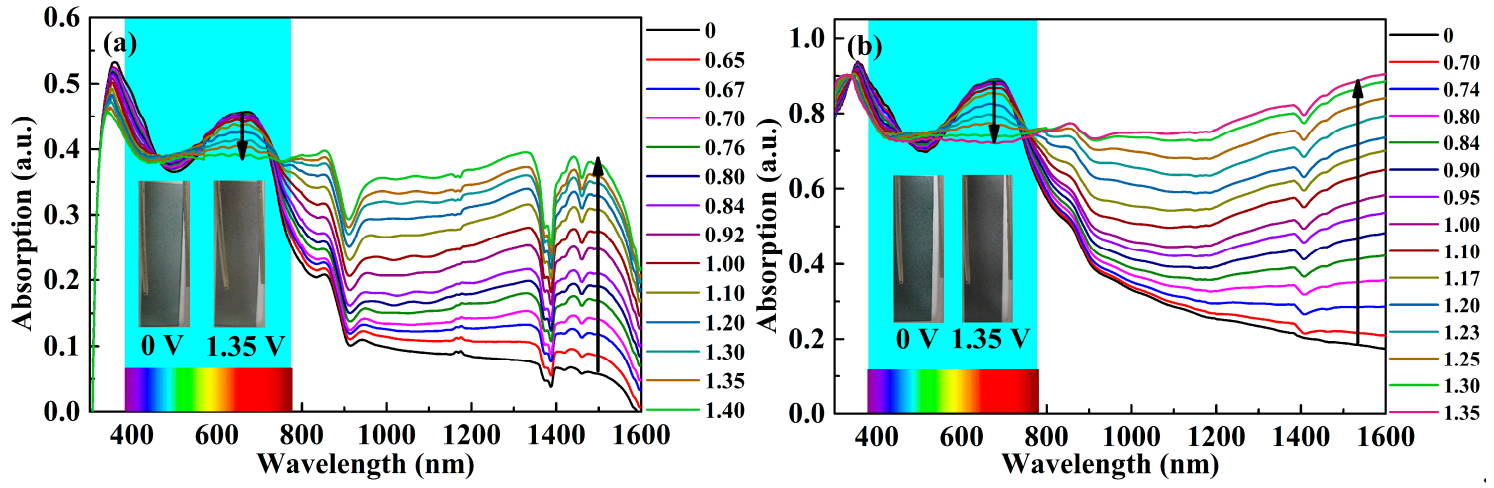

Figure 5. Two-dimensional (2D) spectroelectrochemistry profiles of (a) PITID-1 and (b) PITID-2 copolymer films on ITO-coated conductive slides in a $0.2 \mathrm{M} \mathrm{TBAPF}_{6} / \mathrm{ACN}$ electrolyte solution in different pulse voltages from $0 \mathrm{~V}$ to $1.35 \mathrm{~V}$. The inserted photos show the color cyan in their neutral state $(0 \mathrm{~V}$, left $)$ and the color gray in the oxidized state $(1.35 \mathrm{~V}$, right).

\subsection{Electrochromic Switching Study}

Electrochromic switching study, including chronoamperometry and absorbance tests at specific wavelength under different redox states, is an important factor for evaluating the cycling stability and response time of the electrochromic materials. The parameter can also be used to calculate coloration efficiency of the sprayed films when the spectrophotometer was used in conjunction with electrochemical workstation in the three electrode systems. Electrochromic switching tests for the two copolymers films were studied via multi-potential steps for $300 \mathrm{~s}$ to monitor the change of optical contrast during the switching of the p-doping and p-dedoping process. At the same time, the current curves were recorded in the electrochemical workstation and the consumed charges and response time can be obtained during the single redox process.

For the copolymer PITID-2, the double absorption bands at 675 and $1600 \mathrm{~nm}$ were obtained from the spectroelectrochemical profiles with a wide absorption range at redox states. As shown in Figure 6a, the current curve was recorded and the current intensity decreased slightly in a $4 \mathrm{~s}$ switching interval after $300 \mathrm{~s}$. We selected the second cycle to obtain the consumed charge density of $1.13 \mathrm{mC} / \mathrm{cm}^{2}$ at the wavelength of $675 \mathrm{~nm}$, which were shown in Figure 6b. Figure 6c illustrates the optical transmittance changing percentage of PITID-2 film at $675 \mathrm{~nm}$ by switching the applied square-wave potential steps between 0 and $1.35 \mathrm{~V}$ for a $4 \mathrm{~s}$ time interval. The obtained transmittance contrast was $13 \%$ and then deduced slightly to $12 \%$ when the test time continued to $300 \mathrm{~s}$. It is consistent with the reducing tendency of the current-time curve (shown in Figure 6a). The bleaching and coloration process were highlighted in Figure $6 \mathrm{~d}$. The bleaching process means the absorption percentage change from high value to low value. The coloration process means the transmittance percentage change from low value to high value. For the polymer PITID-2, the coloring response time that cannot be obtained instantly for the naked eyes for humans. Thus, it was calculated at $95 \%$ of a complete coloring and bleaching process to be 2.04 and $0.33 \mathrm{~s}$ in a $4 \mathrm{~s}$ time interval, respectively at $675 \mathrm{~nm}$. Compared with PITID-2, the polymer PITID-1 illustrated similar values. 

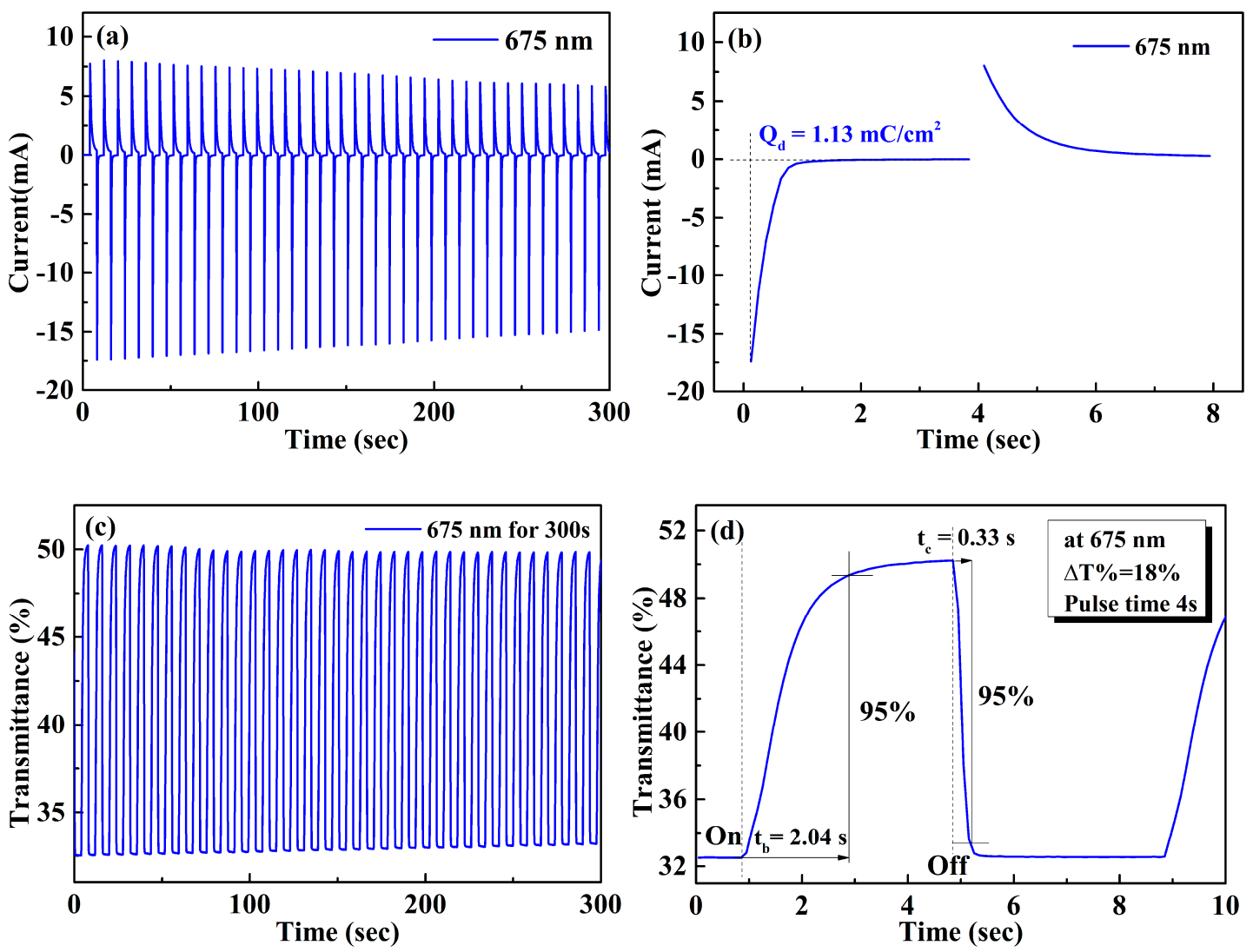

Figure 6. (a) Current-time switching curve of PITID-2 film between 0 and $1.35 \mathrm{~V}$ in a time interval of 4 s. (b) The second cycle of current-time curve. (c) Transmittance-time curve of PITID-2 last for $300 \mathrm{~s}$ at $675 \mathrm{~nm}(\mathrm{~d})$ The bleaching time $\left(t_{\mathrm{b}}\right)$ and the coloration time $\left(t_{\mathrm{c}}\right)$ of PITID-2 at $675 \mathrm{~nm}$.

When the testing absorption wavelength was changed to $1600 \mathrm{~nm}$ for PITID-2, the transmittance changing profiles $(\% \Delta T)$ were monitored as a function of time via UV-vis-NIR spectrophotometer and the switching current was recorded at the same time. Figure 7a depicted that the current underwent a slight loss in intensity during the whole doping and dedoping process between neutral and oxidized state in a time interval of $300 \mathrm{~s}$. The consumed charge density was integrated to be $2.83 \mathrm{mC} / \mathrm{cm}^{2}$ from the second switching cycle (Figure $7 \mathrm{~b}$ ). Figure $7 \mathrm{c}$ illustrated that the transmittance changing percentage can stay from $58 \%$ to $56 \%$ after $300 \mathrm{~s}$, it was consistent with the current-time profile. As shown in Figure $7 \mathrm{~d}$, the $95 \%$ of complete bleaching and coloration times for PITID-2 were 1.35 and $1.50 \mathrm{~s}$, respectively. The fast switching time and high optical contrast in the near infrared region of PITID-2 showed that the material owed potential application in the near infrared area. The kinetic properties of PITID-1 were slightly inferior to that of PITID-2 in several aspects including optical contrast, response time, and consumed charge. The kinetic figures of PITID-1 were shown in Figures S3 and S4 (in Supplementary Materials) in the Supporting Information. The corresponding data of PITID-1 were summarized in Table 3. 

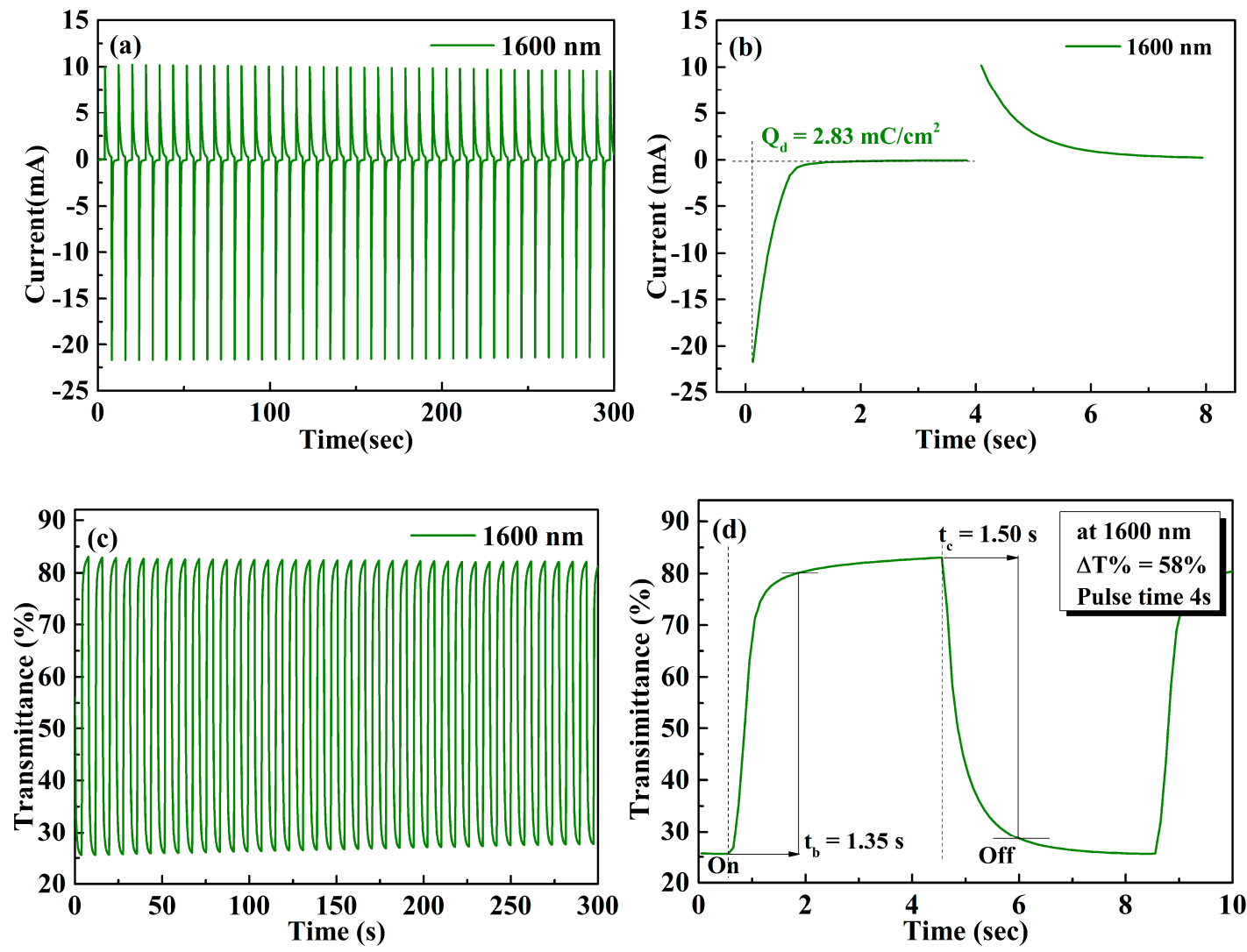

Figure 7. (a) Current-time switching curve of PITID-2 film between 0 and $1.35 \mathrm{~V}$ in a time interval of $4 \mathrm{~s}$. (b) The second cycle of current-time curve. (c) Transmittance-time curve of PITID-2 last for $300 \mathrm{~s}$ at $675 \mathrm{~nm}$. (d) The bleaching time $\left(t_{\mathrm{b}}\right)$ and the coloration time $\left(t_{\mathrm{c}}\right)$ of PITID-2 at $1600 \mathrm{~nm}$.

Coloration efficiency $(\mathrm{CE} ; \eta)$ is an important parameter for evaluating the amount of consumed energy during the coloring or bleaching switching process. The value of $\eta$ can be measured according to the following equation:

$$
\begin{gathered}
H=\Delta O D / \Delta Q_{\mathrm{d}} \\
\Delta \mathrm{OD}=\lg \left(T_{\mathrm{b}} / T_{\mathrm{c}}\right) \\
\Delta Q_{\mathrm{d}}=Q / A
\end{gathered}
$$

where $\triangle O D$ represents the value of optical transmittance contrast between neutral/reduced and oxidized state and $\Delta Q_{\mathrm{d}}$ represents the consumed charge during the process of injected or ejected electrons. According to the equation, the $\eta$ values of PITID-1 were estimated to be 52.94 and $92.92 \mathrm{mC} / \mathrm{cm}^{2}$ at the wavelength of 670 and $1500 \mathrm{~nm}$, respectively. The copolymer PITID-2 owed higher $\eta$ values, which showed 171.52 and $153.08 \mathrm{mC} / \mathrm{cm}^{2}$ at 675 and $1500 \mathrm{~nm}$, respectively. The results showed that the copolymer PITID-2 exhibited better coloration efficiency than PITID-1 and the material had better potential applications in electrochromic areas.

In practical applications of the electrochromic devices, the retention time at a certain voltage difference is dynamically variable, so it is very important to access the dependence of the optical contrasts on the retention times of the polymers during the dynamic switching. For this purpose, the interval times (at the neutral or oxidized state) were set at 10, 4, 2, 1, and back to $10 \mathrm{~s}$, respectively, in the square wave potential step technique, and the optical contrasts were monitored. For PITID-1, the optical contrast at $670 \mathrm{~nm}$ were recorded as $12 \%, 11 \%, 7 \%, 5 \%$, and $9 \%$, respectively, at the interval time of 10, 4, 2, 1, and $10 \mathrm{~s}$ (Figure 8(a1)). As the time interval was reduced from $10 \mathrm{~s}$ to $1 \mathrm{~s}$, the optical contrast was reduced by $31.2 \%$. At the wavelength of $1600 \mathrm{~nm}$, the transmittance contrasts were $40 \%, 33 \%, 23 \%, 16 \%$, and back to $26 \%$ at the interval time of $10,4,2,1$, and back to 10 s, respectively 
(Figure 8(a2)). There was a 30.6\% loss in optical contrast as the switching time was decreased from 10 to $1 \mathrm{~s}$. The relationship between the contrast differences and the time interval applied on the polymers was also investigated in the same way, and similar results were obtained for PITID-2 (Figure 8(b1,b2)). Based on the above data, it was found that optical contrasts have some degree dependence on the interval times, so it was necessary to estimate the response time at specific time intervals.
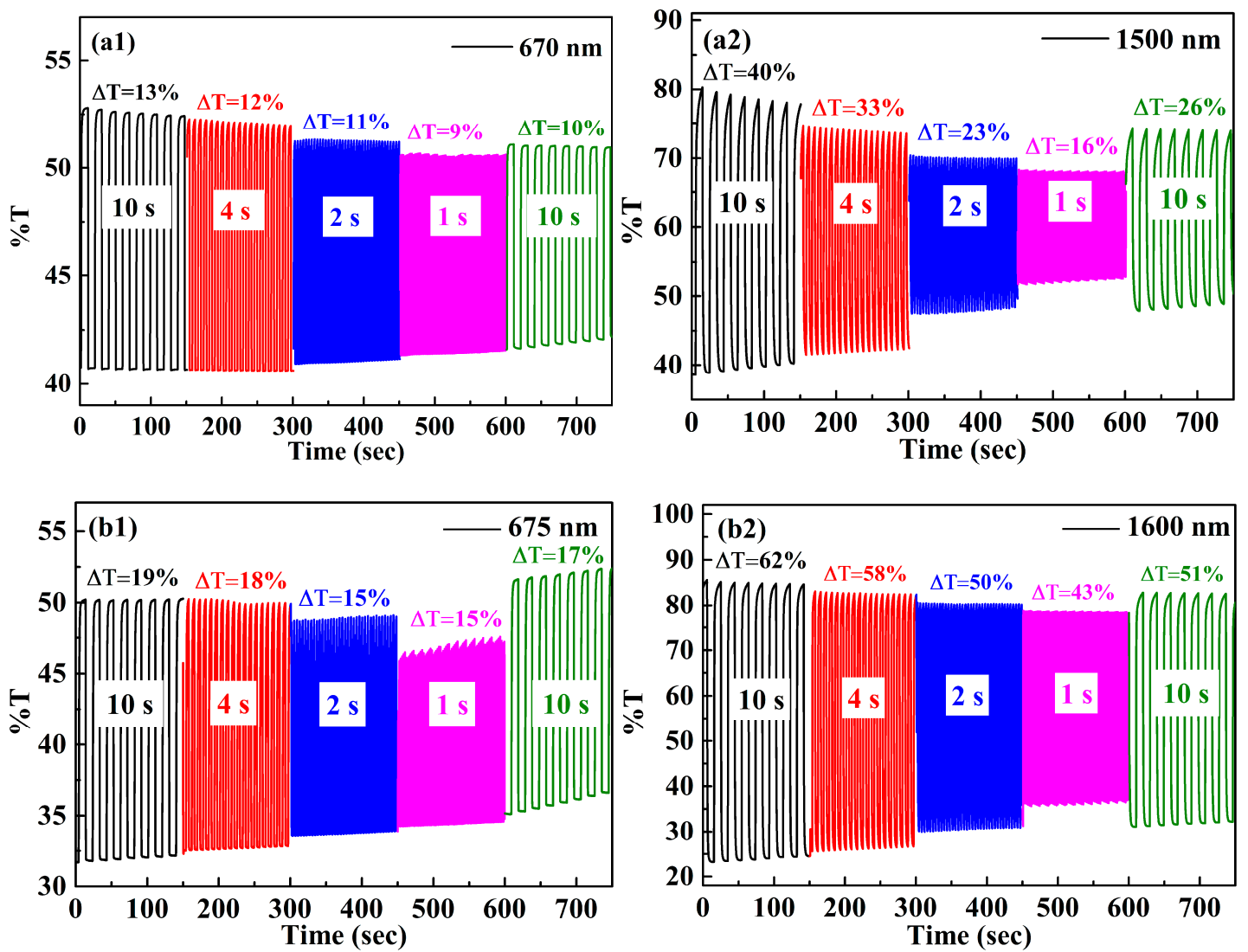

Figure 8. Square-wave potential step for PITID-1 (a1,a2) and PITID-2 (b1,b2) in a $0.2 \mathrm{M} \mathrm{TBAPF}_{6} / \mathrm{ACN}$ solution, by applying the potential from 0 to $1.35 \mathrm{~V}$. (a1) $670 \mathrm{~nm}$, (a2) $1500 \mathrm{~nm}$, (b1) $670 \mathrm{~nm}$, and (b2) $1600 \mathrm{~nm}$. Switching time: $10 \mathrm{~s}$ step, $4 \mathrm{~s}$ step, $2 \mathrm{~s}$ step, $1 \mathrm{~s}$ step, and back to $10 \mathrm{~s}$, and $150 \mathrm{~s}$ for per step.

Table 3. Electrochromic performance of PITID-1 and PITID-2 polymer films.

\begin{tabular}{|c|c|c|c|c|c|c|c|}
\hline \multirow{2}{*}{ Polymer } & \multirow{2}{*}{$\frac{\lambda_{\max }}{\mathrm{nm}}$} & \multirow{2}{*}{$\% \Delta T$} & \multicolumn{2}{|c|}{ a Response Time } & \multirow{2}{*}{$\begin{array}{c}\mathrm{b} \\
\Delta O D\end{array}$} & \multirow{2}{*}{$\frac{{ }^{\mathrm{c}} \Delta Q_{\mathrm{d}}}{(\mathrm{mC} \mathrm{cm}-2)}$} & \multirow{2}{*}{$\frac{{ }^{\mathrm{d}} C E}{\mathrm{~cm}^{2} \mathrm{C}^{-1}}$} \\
\hline & & & $t_{\mathrm{c}}(\mathrm{s})$ & $t_{\mathrm{b}}(\mathrm{s})$ & & & \\
\hline \multirow{2}{*}{ PITID-1 } & 670 & 12 & 2.89 & 0.39 & 0.09 & 1.08 & 52.94 \\
\hline & 1500 & 33 & 2.36 & 2.23 & 0.25 & 2.71 & 92.92 \\
\hline \multirow{2}{*}{ PITID-2 } & 675 & 18 & 2.04 & 0.33 & 0.19 & 1.13 & 171.52 \\
\hline & 1600 & 58 & 1.5 & 1.35 & 0.51 & 3.37 & 153.08 \\
\hline
\end{tabular}

a the response time is calculated at $95 \%$ of the full transmittance change. ${ }^{b} \Delta$ OD represents the value of optical transmittance contrast between neutral/reduced and oxidized state. ${ }^{c} \Delta \mathrm{Q}_{\mathrm{d}}$ represents the consumed charge during the process of injected or ejected electrons. ${ }^{d}$ Coloration efficiencies (CE; $\left.\eta\right)$ are obtained from Equation (1).

\subsection{Colorimetric Analysis}

In order to obtain the color and colorimetric characters of the two materials, the measurement with the CIE $1976 L^{*} a^{*} b^{*}$ color space was used to record the instant color that cannot be distinguished by naked eyes during the variation of applied potentials. Here, $L^{*}$ represents the lightness of the color 
from black to white that can be transformed into values from 0 to $100 . a^{*}$ represents how much red (positive value) versus green (negative value) and $b^{*}$ represents how much yellow (positive value) versus blue (negative value). The positive values of $a^{*}$ and $b^{*}$ mean red and yellow, respectively, or vice versa.

As can be seen from Figure 9(a1,b1), the initial $a^{*}, b^{*}$ values of polymer PITID-1 and polymer PITID-2 located at the negative abscissa, which stood for cyan color in the neutral state. As seen in Figure 9(a1), the color change trajectories of PITID-1 films with different thickness are identical, i.e., from gray to a blue-green color, and then to a gray-blue color, finally turning to a gray color. Polymer PITID-2 had the very similar color changes during the step-by-step p-doping process, as shown in Figure 9(b1). The color space coordinate clearly presented the color changing process under different potentials. The $L^{*}$ values for polymer films (PITID-1) with different thickness are also presented in Figure 9(a2), which have significant changes at $0.6 \mathrm{~V}$ and return to neutral light at $1.35 \mathrm{~V}$. Similar with PITID-1, the $L^{*}$ values for the PITID-2 polymer with different thickness decreased slightly during the p-doping process and back to neutral light at $1.35 \mathrm{~V}$ (Figure 9(b2)). Apart from the similarity in the neutral state color and the oxidized state color, polymer PITID-2 experienced a similar color changing process with that of PITID-1. The polymer eventually changed from a cyan color to a gray color as the polymer switched from the neutral state to the fully oxidized state. In addition, the $L^{*}$ values for the two polymers slightly increased as the potential difference increased from 0 to $1.35 \mathrm{~V}$.
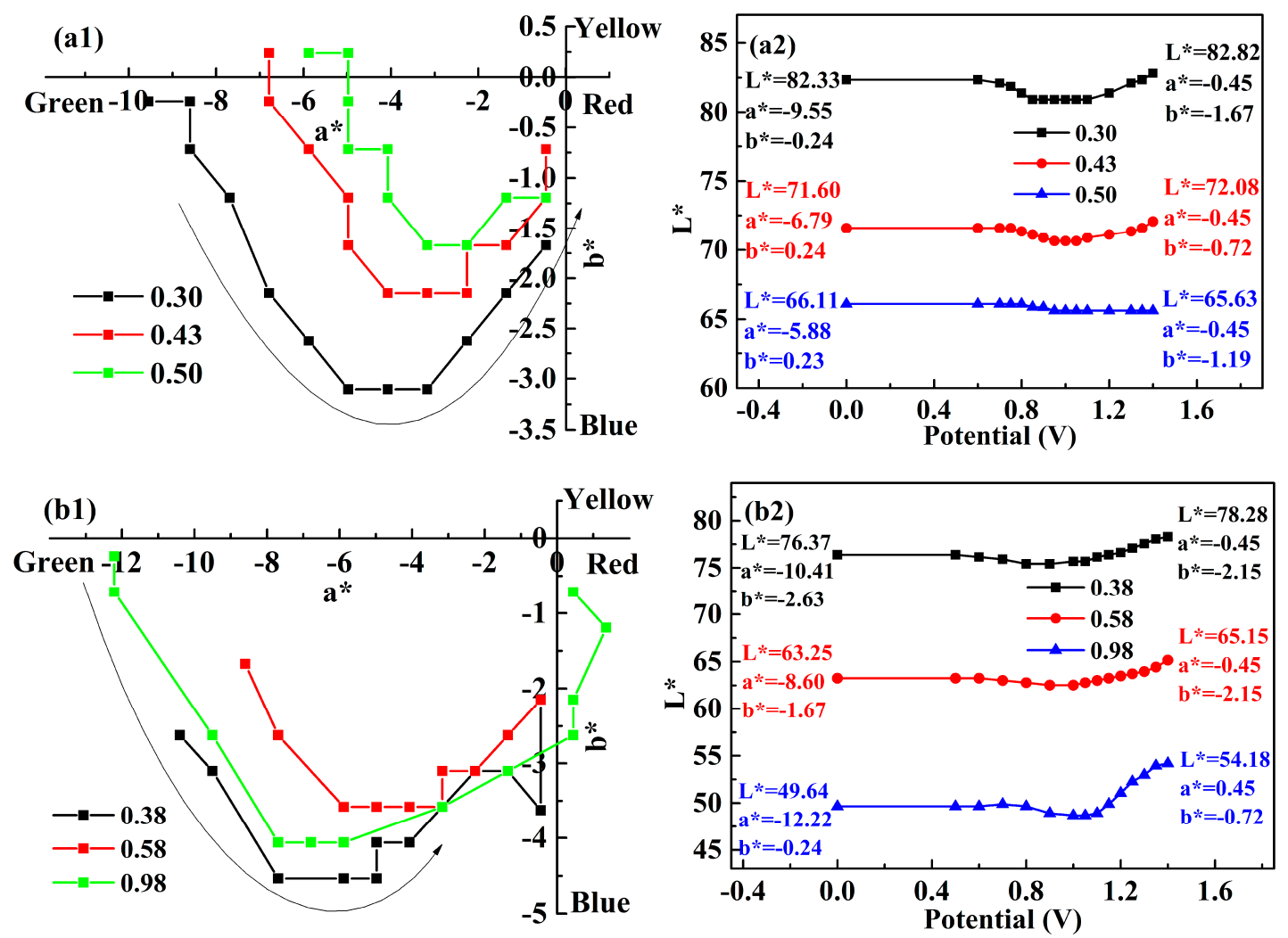

Figure 9. CIE $L^{*} a^{*} b^{*}$ color coordinates for the copolymers PITID-1 (a) and PITID-2 (b) films during p-doping processing from neutral state to oxidized states with three measurable thicknesses.

\subsection{Open Circuit Memory Experiments of the Two Polymers}

Open circuit memory property is an important factor for electrochromic materials or devices, the long residence time can reduce the energy consumption during the switching process of electrochromic devices. The open circuit memory curves of the copolymers films that were applied at constant potential $(0$ or $1.35 \mathrm{~V})$, were recorded at the wavelength of $670 / 1500 \mathrm{~nm}$ and $675 / 1600 \mathrm{~nm}$ for $1 \mathrm{~s}$ for every 120 s time interval for PITID-1 and PITID-2, respectively. As shown in Figure 10a, the film of 
PITID-1 kept an unchangeable transmittance at $670 \mathrm{~nm}$ when the film was in the neutral state. However, the profile show jagged curve as the polymer was kept in the oxidized state by intermittent potential at $1.35 \mathrm{~V}$ for $1200 \mathrm{~s}$, unstable but recoverable absorption retention characteristics. Similar variation tendency can be obtained for PITID-2 in Figure 10b. The results show that the two materials show good optical memory at the neutral state, and the memory in the oxidized state could be compensated by the pulse applied voltages.
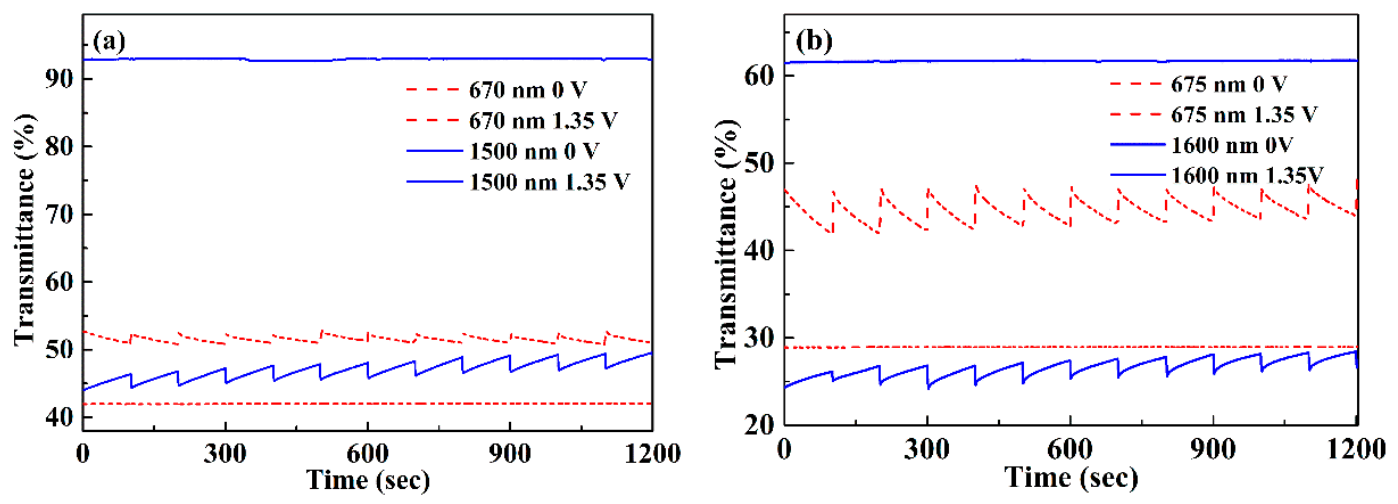

Figure 10. Open circuit stability of the sprayed films at 670 and $1500 \mathrm{~nm}$ for copolymer PITID-1 (a) and the film at 675 and $1600 \mathrm{~nm}$ for copolymer PITID-2 (b). The pulse voltage was applied for $1 \mathrm{~s}$ for every interval time of $120 \mathrm{~s}$ to recover the initial transmittance at constant neutral or oxidized state. Straight line: neutral state, Jagged line: oxidized state. Dotted line: 670/675 nm, Solid line: 1500/1600 nm.

\subsection{Thermal Properties}

The thermal behaviors and stabilities of the conjugated materials PITID-1 and PITID-2 were studied via thermogravimetric analysis (TG; TGA) and differential thermogravimetric (DTG) methods. Samples were heated at the heating rate of $10^{\circ} \mathrm{C} / \mathrm{min}$ from room temperature to $750^{\circ} \mathrm{C}$. Several physical parameters are obtained from TG and DTG curves (Figure 11). The initial decomposition temperature $\left(T_{\mathrm{d}}\right)$ refers to the point at which a $5 \%$ weight loss of the material occurs. The prestissimo decomposition temperature $\left(T_{\mathrm{p}}\right)$ represents the inflection point that can be drawn from the peak value of DTG curve. The extrapolated finish temperature $\left(T_{\mathrm{ef}}\right)$ is the temperature at the intersection point of the tangent line of the mid-section and the tail section of the TG curve. The $T_{\mathrm{ei}}$ temperature refers to the intersection of the tangent of the baseline and the tangent line of the mid-section curve of the TG curve. The \% char refers to the percentage of the residual carbon ash to the quality of the initial samples at the final temperature $\left(750{ }^{\circ} \mathrm{C}\right.$ in this case). The data were summarized in Table 4 . TGA plots showed that both copolymers exhibited good thermal stabilities in $\mathrm{N}_{2}$ atmosphere, with the $\mathrm{T}_{\mathrm{d}}$ temperatures were observed at $422^{\circ} \mathrm{C}$ (PITID-1) and $399^{\circ} \mathrm{C}$ (PITID-2). The high decomposition temperature may benefit from the rigid conjugated groups with long alkyl side chains. PITID-1 has a $T_{\mathrm{p}}$ temperature of $464{ }^{\circ} \mathrm{C}$, a $T_{\text {ei }}$ temperature of $427^{\circ} \mathrm{C}$, a $T_{\text {ef }}$ temperature of $495^{\circ} \mathrm{C}$. The $\%$ char of the polymers were $20 \%$ for PITID-1 and $41 \%$ for PITID-2. The polymer PITID-2 possessed similar thermal parameters to that of PITID-1. The materials can endure over $400{ }^{\circ} \mathrm{C}$ in test condition without decomposition and can meet the requirements on environmental temperature for various electrochromic devices. 


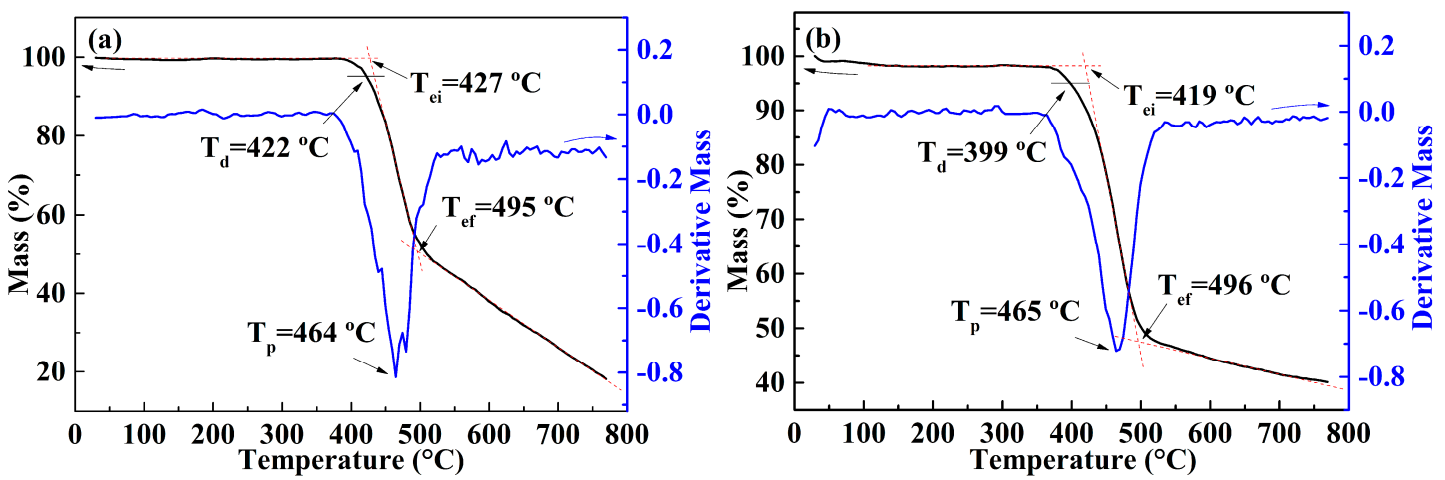

Figure 11. Thermogravimetric (TG) and differential thermogravimetric (DTG) curves for PITID-1 (a) and PITID-2 (b).

Table 4. TG and DTG data for PITID-1 and PITID-2.

\begin{tabular}{cccccc}
\hline Compound & $\boldsymbol{T}_{\text {ei }}\left({ }^{\circ} \mathbf{C}\right)$ & $\boldsymbol{T}_{\text {ef }}\left({ }^{\circ} \mathbf{C}\right)$ & $\boldsymbol{T}_{\mathbf{p}}\left({ }^{\circ} \mathrm{C}\right)$ & $\boldsymbol{T}_{\mathbf{d}}\left({ }^{\circ} \mathbf{C}\right)$ & $\%$ char \\
\hline PITID-1 & 427 & 495 & 464 & 422 & 20 \\
PITID-2 & 419 & 496 & 465 & 399 & 41 \\
\hline
\end{tabular}

\section{Conclusions}

The two random polymers PITID-X $(X=1,2)$ based on indolo[3,2-b]carbazole, isoindigo and thiophene units were successfully synthesized via Stille cross-coupling polymerization with different raw material feed ratios. It was feasible to obtain the color of the materials with two characteristic absorption peaks by adopting the strategy of changing variable donor-to-acceptor ratio of the copolymers. ${ }^{1} \mathrm{H}$ NMR, IR, XPS measurements were carried out to confirm the structural units of the copolymer chains. TGA curves showed that the polymers owed stable heat tolerance property over $400{ }^{\circ} \mathrm{C}$. The $\mathrm{CV}$ curves of the polymers showed one pair of redox peaks, which suggested the obvious reversible p-type doping/dedoping ability. The UV-vis-NIR profiles of the films illustrated that the spray-coated films showed more obvious red shift than that of corresponding polymer solutions. The results of faster response time, higher optical contrast in NIR, and better kinetic stability showed that the electrochromic properties of PITID-2 were superior to that of PITID-1. For PITID-2, it had a color change from cyan (neutral state) to gray (oxidized state), showed good electrochromic property due to low optical band gap of $1.54 \mathrm{eV}$. The materials also illustrated fast bleaching/coloring response time of $2.04 / 0.33 \mathrm{~s}$ and $1.50 / 3.37 \mathrm{~s}$, good coloration efficiency of 171.52 and $153.08 \mathrm{~cm}^{2} \mathrm{C}^{-1}$ and satisfactory optical contrast of $18 \%$ and $58 \%$ at wavelengths of 675 and $1600 \mathrm{~nm}$, respectively.

Supplementary Materials: The following are available online at http://www.mdpi.com/2073-4360/11/10/1626/s1. Figure S1: ${ }^{1} \mathrm{H}$ NMR spectra of the copolymers PITID-1 (a) and PITID-2 (b). Figure S2: High-resolution XPS spectra of the copolymer PITID-1; (a) survey scan; (b) C 1s; (c) N 1s; (d) S 2p; (e) O 1s, The raw and fitted curves were recorded in solid and dotted lines, respectively. Figure S3: (a) Current-time switching curve of PITID-1 film between 0 and $1.35 \mathrm{~V}$ in a time interval of $4 \mathrm{~s}$; (b) The second cycle of current-time curve; (c) Transmittance-time curve of PITID-1 last for $300 \mathrm{~s}$ at $670 \mathrm{~nm}$; (d) The bleaching time $\left(\mathrm{t}_{\mathrm{b}}\right)$ and the coloration time ( $\mathrm{t}_{\mathrm{c}}$ ) of PITID-1 at $670 \mathrm{~nm}$. Figure S4: (a) Current-time switching curve of PITID-1 film between 0 and $1.35 \mathrm{~V}$ in a time interval of $4 \mathrm{~s}$; (b) The second cycle of current-time curve; (c) Transmittance-time curve of PITID-1 last for $300 \mathrm{~s}$ at $1500 \mathrm{~nm}$; (d) The bleaching time $\left(t_{b}\right)$ and the coloration time $\left(t_{c}\right)$ of PITID-1 at $1500 \mathrm{~nm}$.

Author Contributions: Y.Z. (Yuling Zhang) synthesized the monomers and conducted the experiments, and drafted the manuscript. S.C. contributed reagents/materials/analysis tools. Y.Z. (Yan Zhang) and H.D. analyzed the data. J.Z. supervised the work and critically revised the manuscript.

Acknowledgments: The work was financially supported by the National Natural Science Foundation of China (51473074, 21601079), Natural Science Foundation of Shandong Province (ZR2019MEM031).

Conflicts of Interest: The authors declare no conflict of interest. 


\section{References}

1. Eh, A.L.-S.; Tan, A.W.M.; Cheng, X.; Magdassi, S.; Lee, P.S. Recent advances in flexible electrochromic devices: Prerequisites, challenges, and prospects. Energy Technol. 2018, 6, 33-45. [CrossRef]

2. Beaujuge, P.M.; Ellinger, S.; Reynolds, J.R. The donor-acceptor approach allows a black-to-transmissive switching polymeric electrochrome. Nat. Mater. 2008, 7, 795-799. [CrossRef] [PubMed]

3. Udum, Y.A.; Durmus, A.; Gunbas, G.E.; Toppare, L. Both p- and n-type dopable polymer toward electrochromic applications. Org. Electron. 2008, 9, 501-506. [CrossRef]

4. Amb, C.M.; Dyer, A.L.; Reynolds, J.R. Navigating the color palette of solution-processable electrochromic polymers. Chem. Mater. 2011, 23, 397-415. [CrossRef]

5. Neo, W.T.; Ye, Q.; Chua, S.-J.; Xu, J.W. Conjugated polymer-based electrochromics: Materials, device fabrication and application prospects. J. Mater. Chem. C 2016, 4, 7364-7376. [CrossRef]

6. Teran, N.B.; Reynolds, J.R. Discrete donor-acceptor conjugated systems in neutral and oxidized states: Implications toward molecular design for high contrast electrochromics. Chem. Mater. 2017, 29, 1290-1301. [CrossRef]

7. Liu, X.; Xie, Y.; Cai, X.; Li, Y.; Wu, H.; Su, S.-J.; Cao, Y. Synthesis and photovoltaic properties of A-D-A type non-fullerene acceptors containing isoindigo terminal units. RSC Adv. 2015, 5, 107566-107574. [CrossRef]

8. Abraham, S.; Mangalath, S.; Sasikumar, D.; Joseph, J. Transmissive-to-black electrochromic devices based on cross-linkable tetraphenylethene-diphenylamine derivatives. Chem. Mater. 2017, 29, 9877-9881. [CrossRef]

9. Groenendaal, L.; Zotti, G.; Aubert, P.H.; Waybright, S.M.; Reynolds, J.R. Electrochemistry of poly(3,4-alkylenedioxythiophene) derivatives. Adv. Mater. 2003, 15, 855-879. [CrossRef]

10. Zhao, G.; Dong, H.; Zhao, H.; Jiang, L.; Zhang, X.; Tan, J.; Meng, Q.; Hu, W. Substitution effect on molecular packing and transistor performance of indolo[3,2-b]carbazole derivatives. J. Mater. Chem. 2012, 22, 4409-4417. [CrossRef]

11. Lu, Y.; Ding, Y.; Wang, J.; Pei, J. Research progress in isoindigo-based polymer field-effect transistor materials. Chin. J. Org. Chem. 2016, 36, 2272-2283. [CrossRef]

12. Cho, I.; Park, S.K.; Kang, B.; Chung, J.W.; Kim, J.H.; Cho, K.; Park, S.Y. Design, synthesis, and versatile processing of indolo[3,2-b]indole-based $\pi$-conjugated molecules for high-performance organic field-effect transistors. Adv. Funct. Mater. 2016, 26, 2966-2973. [CrossRef]

13. Hwang, J.; Park, J.; Kim, Y.J.; Ha, Y.H.; Park, C.E.; Chung, D.S.; Kwon, S.-K.; Kim, Y.-H. Indolo[3,2-b]indole-containing donor-acceptor copolymers for high-efficiency organic solar cells. Chem. Mater. 2017, 29, 2135-2140. [CrossRef]

14. Zhong, W.; Xu, C.; Xiao, B.; Fan, L.; Wu, H.; Zhang, B.; Yang, W. High molecular weight broad band-gap polymers based on indolo[3,2-b]carbazole and thiazolo[5,4-d]thiazole derivatives for solar cells. Polym. Sci. Ser. B 2016, 58, 587-593. [CrossRef]

15. Zhang, Y.; Ma, Y.; Kong, L.; Tian, Y.; Yang, J. A novel indolo[3,2- b ]carbazole derivative with D- $\pi$-A structure exhibiting aggregation-enhanced emission and mechanofluorochromic properties. Dyes Pigm. 2018, 159, 314-321. [CrossRef]

16. Zhang, J.; Chen, Z.; Wang, X.-Y.; Guo, S.-Z.; Dong, Y.-B.; Yu, G.-A.; Yin, J.; Liu, S.-H. Redox-modulated near-infrared electrochromism, electroluminochromism, and aggregation-induced fluorescence change in an indolo[3,2-b]carbazole-bridged diamine system. Sens. Actuators B 2017, 246, 570-577. [CrossRef]

17. Shi, H.; Yuan, J.; Wu, X.; Dong, X.; Fang, L.; Miao, Y.; Wang, H.; Cheng, F. Two novel indolo[3,2-b]carbazole derivatives containing dimesitylboron moieties: Synthesis, photoluminescent and electroluminescent properties. New J. Chem. 2014, 38, 2368-2378. [CrossRef]

18. Mula, S.; Leclerc, N.; Leveque, P.; Retailleau, P.; Ulrich, G. Synthesis of indolo[3,2- b]carbazole-based boron complexes with tunable photophysical and electrochemical properties. J. Org. Chem. 2018, 83, 14406-14418. [CrossRef]

19. Qian, X.; Shao, L.; Li, H.; Yan, R.; Wang, X.; Hou, L. Indolo[3,2-b]carbazole-based multi-donor- $\pi$-acceptor type organic dyes for highly efficient dye-sensitized solar cells. J. Power Sources. 2016, 319, 39-47. [CrossRef]

20. Reig, M.; Puigdollers, J.; Velasco, D. Molecular order of air-stable p-type organic thin-film transistors by tuning the extension of the $\pi$-conjugated core: The cases of indolo[3,2-b]carbazole and triindole semiconductors. J. Mater. Chem. C 2015, 3, 506-513. [CrossRef] 
21. Lengvinaite, S.; Grazulevicius, J.V.; Grigalevicius, S.; Gu, R.; Dehaen, W.; Jankauskas, V.; Zhang, B.; Xie, Z. Indolo[3,2-b]carbazole-based functional derivatives as materials for light emitting diodes. Dyes Pigm. 2010, 85, 183-188. [CrossRef]

22. Xu, Z.; Zhang, Y.; Wang, B.; Liu, Z.; Zhao, J.; Xie, Y. Yellow-to-blue switching of indole[3,2-b]carbazole-based electrochromic polymers and the corresponding electrochromic devices with outstanding photopic contrast, fast switching speed, and satisfactory cycling stability. Electrochim. Acta 2019, 302, 373-384. [CrossRef]

23. Wang, E.; Ma, Z.; Zhang, Z.; Vandewal, K.; Henriksson, P.; Inganas, O.; Zhang, F.; Andersson, M.R. An easily accessible isoindigo-based polymer for high-performance polymer solar cells. J. Am. Chem. Soc. 2011, 133, 14244-14247. [CrossRef] [PubMed]

24. Xie, H.; Wang, M.; Kong, L.; Zhang, Y.; Ju, X.; Zhao, J. The optimization of donor-to-acceptor feed ratios with the aim of obtaining black-to-transmissive switching polymers based on isoindigo as the electron-deficient moiety. RSC Adv. 2017, 7, 11840-11851. [CrossRef]

25. Gu, H.; Ming, S.L.; Lin, K.W.; Chen, S.; Liu, X.M.; Lu, B.Y.; Xu, J.K. Isoindigo as an electron-deficient unit for high-performance polymeric electrochromics. Electrochim. Acta 2018, 260, 772-782. [CrossRef]

26. Deng, P.; Zhang, Q. Recent developments on isoindigo-based conjugated polymers. Polym. Chem. 2014, 5, 3298-3305. [CrossRef]

27. Stalder, R.; Puniredd, S.R.; Hansen, M.R.; Koldemir, U.; Grand, C.; Zajaczkowski, W.; Mullen, K.; Pisula, W.; Reynolds, J.R. Ambipolar charge transport in isoindigo-based donor-acceptor polymers. Chem. Mater. 2016, 28, 1286-1297. [CrossRef]

28. Liu, Y.; Wang, M.; Zhao, J.; Cui, C.; Liu, J. Effects of alkyl or alkoxy side chains on the electrochromic properties of four ambipolar donor-acceptor type polymers. RSC Adv. 2014, 4, 52712-52726. [CrossRef]

29. Randell, N.M.; Radford, C.L.; Yang, J.; Quinn, J.; Hou, D.; Li, Y.; Kelly, T.L. Effect of acceptor unit length and planarity on the optoelectronic properties of isoindigo-thiophene donor-acceptor polymers. Chem. Mater. 2018, 30, 4864-4873. [CrossRef]

30. Gross, Y.M.; Trefz, D.; Tkachov, R.; Untilova, V.; Brinkmann, M.; Schulz, G.L.; Ludwigs, S. Tuning aggregation by regioregularity for high-performance n-type $\mathrm{P}\left(\mathrm{NDI}_{2} \mathrm{OD}-\mathrm{T}_{2}\right)$ donor-acceptor copolymers. Macromolecules 2017, 50, 5353-5366. [CrossRef]

31. Liu, X.; Kong, L.; Du, H.; Zhang, Y.; Zhao, J.; Xie, Y. Synthesis and electrochromic properties of electrochromic polymers based on propylenedioxythiophene, diketopyrrolopyrrole and benzodithiophene units. Org. Electron. 2019, 64, 223-235. [CrossRef]

32. Mery, A.; Bernard, P.; Valero, A.; Alper, J.P.; Herlin-Boime, N.; Haon, C.; Duclairoir, F.; Sadki, S. A polyisoindigo derivative as novel n-type conductive binder inside Si@C nanoparticle electrodes for Li-ion battery applications. J. Power Sources 2019, 420, 9-14. [CrossRef]

33. Dante, R.C.; Chamorro-Posada, P.; Vázquez-Cabo, J.; Rubiños-López, Ó.; Sánchez-Árevalo, F.M.; Huerta, L.; Martín-Ramos, P.; Lartundo-Rojas, L.; Ávila-Vega, C.F.; Rivera-Tapia, E.D.; et al. Nitrogen-carbon graphite-like semiconductor synthesized from uric acid. Carbon 2017, 121, 368-379. [CrossRef]

34. Ming, S.; Zhen, S.; Lin, K.; Zhao, L.; Xu, J.; Lu, B. Thiadiazolo[3,4-c]pyridine as an acceptor toward fast switching green donor acceptor type electrochromic polymer with low bandgap. ACS Appl. Mater. Interfaces 2015, 7, 11089-11098. [CrossRef] [PubMed]

(C) 2019 by the authors. Licensee MDPI, Basel, Switzerland. This article is an open access article distributed under the terms and conditions of the Creative Commons Attribution (CC BY) license (http://creativecommons.org/licenses/by/4.0/). 